\title{
Thymic Tumor pNO TNM Finding v8
}

National Cancer Institute

\section{Source}

National Cancer Institute. Thymic Tumor pNO TNM Finding v8. NCI Thesaurus. Code C136316.

Thymic tumor without regional lymph node metastasis. (from AJCC 8th Ed.) 